\title{
Allometric Equations for Aboveground Biomass Estimations of Four Dry Afromontane Tree Species
}

Getaneh Gebeyehu ( $\nabla$ getanehgebeyehu@yahoo.com )

Addis Ababa University College of Natural Sciences

\section{Teshome Soromessa}

Addis Ababa University

\section{Tesfaye Bekele}

Ethiopian Environment and Forestry Research Institute

\section{Demel Teketay}

Botswana University of Agriculture and Natural Resources

\section{Research}

Keywords: Allometric models, Biomass, Prediction, Semi destructive

Posted Date: November 6th, 2020

DOI: https://doi.org/10.21203/rs.3.rs-102592/v1

License: (9) This work is licensed under a Creative Commons Attribution 4.0 International License. Read Full License 


\title{
Allometric equations for aboveground biomass estimations of four dry Afromontane tree species
}

Getaneh Gebeyehu ${ }^{1 *}$, Teshome Soromessa ${ }^{2}$, Tesfaye Bekele ${ }^{3}$, Demel Teketay ${ }^{4}$

(*Correspondence: getanehgebeyehu@yahoo.com, P.O. Box 18, Assosa, Ethiopia)

\begin{abstract}
Background: Tree species based developing allometric equations are important because they contain the largest proportion of total biomass and carbon stocks of forests. Studies on developing and validating the species-specific allometric models (SSAM) remain insufficient that may result to biomass estimation errors in the forests. The purpose of this study is to determine the wood density of four tree species and develop and validate the accuracy of allometry for biomass estimations. A total of 103 sample trees representing four species were harvested semi-destructively. The species specific allometric equations (SSAM) were developed using aboveground biomass (AGB in $\mathrm{kg}$ ) as dependent variable, and three of the predictor's variables: diameter at beast height (DBH in $\mathrm{cm}$ ), height $\left(\mathrm{H}\right.$ in $\mathrm{m}$ ) and wood density (WD in $\mathrm{g} \mathrm{cm}^{-}$ $\left.{ }^{3}\right)$. The relation between dependent and independent variables were tested using multiple correlations $\left(\mathrm{R}^{2}\right)$. The model selection and validation was based on statistical significance of model parameter estimates, Akaike Information Criterion (AIC), adjusted coefficient of determination $\left(\mathrm{R}^{2}\right)$, residual standard error (RSE) and mean relative error (MRE).
\end{abstract}

Results: The results showed that the AGB correlated significantly with diameter at breast height $\left(R^{2}>0.944, P<0.001\right)$, and tree height $\left(R^{2}>0.742, P<0.001\right)$. The species-specific allometric models, which include DBH, $\mathrm{H}$ and WD predicted AGB with high-model fit $\left(\mathrm{R}^{2} \geq 93.6 \%, \mathrm{P}<\right.$ 0.001). These models for biomass estimations produced small MRE (1.50-3.40\%) and AIC ($7.04-12.84$ ) compared to a single predictor (MRE:-0.4 - 20.1\%; AIC: $-7.25-35.29$ ). The SSAM also predicted AGB against predictors with high-model fit $\left(\mathrm{R}^{2} \geq 93.6 \%, \mathrm{P}<0.001\right)$ and small MRE: 1.50 - 3.40\% compared to existing general allometric models (MRE: - 31.3 $11.31 \%)$.

Conclusions: The research confirmed that the inclusion of DBH, H, and WD in the SSAM predicted AGB with small bias than a single or two predictors. The wood density values of those studied species can be used as the references for biomass estimations using general allometric 
equations. The study contributes to species-specific allometric models for understanding the total biomass estimation of species. Therefore, the application of species-specific allometric models should be considered in biomass estimations of forests.

Keywords: Allometric models, Biomass, Prediction, Semi destructive

\section{Background}

Forests in general and trees in particular play an important role in the global carbon cycle as carbon sinks. The aboveground portions of trees hold significant amounts of biomass greater than $80 \%$ of the total tree biomass, mostly held in stem wood and branches (Henry et al. 2010; Ebuy et al. 2011). In contrast, deforestation for agricultural purpose and degradation like selective harvesting affect directly the aboveground biomass of trees (Gibbs et al. 2007). This fact calls for accurate estimation of tree biomass and assessing sequestration of carbon in biomass components including leaves, trunk, branches and roots (Návar 2009). The aboveground biomass of trees plays an important role to estimate the amount of carbon sequestered in appropriate management systems of forests or that can be emitted when forests are destroyed (Mokria et al. 2018). These trees role in climate change mitigation have led to increase efforts in developing methods for aboveground biomass (AGB) estimations. In addition to, the species differences, site fertility, and forest types in the natural forests are likely to influence the quantity of AGB of trees.

Sustainable forests management systems depend on information on the growing stock, which requires estimation of tree biomass. These systems require establishing biomass estimation methods and reporting mechanisms for carbon finance. The most accurate biomass estimation method includes developing general, site-specific and species-specific allometric models (Chave et al. 2005; Chave et al. 2014). Many general allometric equations have been developed to predict the aboveground biomass of forests (Brown et al. 1989; Chave et al. 2005; Chave et al. 2014). However, most of the allometric equations are used to estimate biomass of tropical rainforests (43\%) compared with tropical dry forests (16\%) (Henry et al. 2010). Such allometric equations are constructed on the base of theoretical considerations and experimental studies. The theoretical study supports the existence of a strong relationship between the diameter at breast height and biomass of trees and the relation called a power law (Vieilledent et al. 2012). Based on this theory, several general allometric equations are developed relating biomass with 
dendrometric variables like diameter of trees (Chojnacky 2002; Návar 2009; Vieilledent et al. 2012). However, the simple theoretical study shows poor relation between diameter and biomass (Chave et al. 2005). For this reason, a single predictor variable of diameter might lead to overestimation of tree biomass. To reduce uncertainty of biomass estimations, many previous studies suggest that the inclusion of height and wood density of trees are important (Henry et al. 2010; Chave et al. 2014).

Data gathering for biomass estimations requires two sampling techniques. The first technique for the development of allometric models requires destructive harvesting in the field (Brown et al. 1989; Picard et al. 2012; Chave et al. 2014; Djomo et al. 2016). However, this technique requires high financial resources and involves cutting and weighing of all partitions of trees that may also lead to forest degradation. The second method of developing allometric models for tree biomass estimation is recommended which may constitute the semi-destructive technique (Picard et al. 2012). This technique involves only the small branches are harvested and measured in the field while the trunk and large branches of trees cannot be felled.

Despite the availability of several methodologies to compute forest biomass in tropical regions from ground sampling, there are still fundamental problems associated with sampling, measurement, and allometric uncertainty that must be addressed by the researchers (Chave et al. 2014; Djomo et al. 2016).The development of species-specific allometric equations is thus important and needed in a localized relationship when the generalized equations may not adequately represent all forest types (Gibbs et al. 2007). The lack of reliable equations in many tropical forests especially in Africa that may become a major source of uncertainty in biomass estimates (Henry et al. 2010). This requires destructive sampling of trees to check the validity of an allometric equation for specific locations (Brown 2002). On the base of lack of validity for accurate biomass estimations, the previous studies have attempted to develop species-specific allometric equations and biomass estimations in few species and forest types in the natural forests of Ethiopia (Henry et al. 2010). To date, the species-specific allometric equations are developed using the semi-destructive techniques for biomass estimations of large trees such as Olea europaea L. subsp. cuspidata (Wall. ex DC.) in Mana Angetu Forest (Kebede and Soromessa 2018); Juniperus procera Hochst. ex Endl. and Podocarpus falcatus in Mirb of WofWasha Forest (Worku and Soromessa 2015) and Acacia abyssinica Hochst. ex Benth. in dry 
forests in northern Ethiopia (Solomon et al. 2017). In addition to, the species-specific allometric models are developed and the biomasses in the dry Afromotane trees such as Allophyllus abyssinicus (Hochst.), Olinia rochetiana A. Juss, Rhus glutinosa Hochst. Ex A. Rich., and Scolopia theifolia Gilg are determined in Chilimo forests of Ethiopia (Tesfaye et al. 2016). The biomass of small size trees/shrubs of Calpurnia aurea Benth., Dodonaea angustifolia L. F., Cadia purpurea Ait, Tarchonanthus camphorantus L., Acokanthera schimperi (A. DC.) Benth. \& Hook.f. ex Schweinf., and Euclea racemosa Murray subsp. Schimperi (A. DC) F. White are also quantified using localized allometric models in the northern Ethiopia (Tetemke et al. 2019). This indicates that the species-specific allometric models and biomass estimations remain limited compared to existing indigenous tree species in general and wood density determination in particular in the forests of the country. Therefore, the objectives of this study are to determine the wood density of four Afromontane tree species; develop and validate the accuracy of allometry for biomass estimations, and compare the species-specific allometry from existing generalized equations for biomass estimations. The equations developed are based on the dendrometric variables (diameter, height and wood density) of trees and AGBs are estimated using these equations.

\section{Methods}

\subsection{Study area description}

The study was conducted in the Banja district of Awi Zone of Amhara National Regional State (ANRS), northwestern Ethiopia (Fig. 1). It is located at $10^{\circ} 30^{\prime}$ to $11^{\circ} 05^{\prime} \mathrm{N}$ and $36^{\circ} 20^{\prime}$ to $37^{\circ} 00^{\prime}$

E. The study was carried out in the Afromontane forests called Apini (693.33 ha) and Dabkuli (509.79 ha) which are managed by the regional state. The topography of the area is a relatively intermediate slope (10 to $15 \%$ ) and altitudes range from 2000 to $2300 \mathrm{~m}$. The volcanic origins of soils in the study area mainly give reddish or brown in color, draining freely and of medium to heavy texture.

The annual rainfall pattern is unimodal with a maximum rainy season from June to October. The average annual rainfall in the area is $2241 \mathrm{~mm}$. The annual monthly temperature ranges from 8.1 to $30.5^{\circ} \mathrm{C}$ with average temperatures of $18.7^{\circ} \mathrm{C}$. The vegetation type belongs to the dry Afromontane forest. The forest vegetation structurally consists of upper canopy trees like Prunus 
africana (Hook. f.) Kalkm., Albizia gummifera (J.F. Gmel.) C.A. Sm. and Apodytes dimidiata E. Mey. ex Am. and middle canopy trees are Croton macrostachyus Del., Allophyllus abyssinicus (Hochst) Radlkofer, Celtis africana Burm.f, Millettia ferruginea (Hochst.) Bak, and lower canopy trees as Rothmannia urcelliformis, Lepidotrichilia volkensii (Gilrke) Leroy, Teclea nobilis Del. and Ehretia cymosa Thonn.(Gebeyehu et al. 2019). The distinguishing characteristics species of dry Afromontane forests like Juniperus procera Hochst and Olea europaea L. subsp. cuspidata (Wall. ex DC.) in the upper canopy are degraded and found very rarely.

\subsection{Description of tree species}

For this study, four tree species such as Ehretia cymosa Thonn, Lepidotrichilia volkensii (Giirke) Leroy, Rothmannia urcelliformis (Hiern) Robyns and Teclea nobilis Del. which provide a broad range of economic importance being were selected for developing allometric equations. $E$. cymosa Thonn (Boraginaceae) commonly occurs in evergreen forest and forest patches, usually on steep mountainsides nearly in all regions at an altitude range of 1,400 - 2,300 m in Ethiopia. It is a common widespread species persist in disturbed areas. E. cymosa provides wide economic and ecological importance such as traditional medicine (Gakuubi and Wanzala 2012) and construction (Seta et al. 2013); and edible fruits (Addis et al. 2013; Sina and Degu 2015); and fuelwood, erosion control and fencing (Gina et al. 2014). L. volkensii (Giirke) Leroy (Meliaceae) inhabits in an understory of moister forests ranging an altitude of $1050-2800 \mathrm{~m}$. Its distribution ranges from Ethiopia to Malawi. This species supplies an economic as well as ecologically important. R. urcelliformis (Hiern) Robyns (Rubiaceae) is a common shrubby tree in moist or dry forest, often near rivers. The species supplies edible fruits (Addis et al. 2013; Sina and Degu 2015) and widely used in traditional medicine (Neuwinger 1996). T. nobilis Del. (Rutaceae) is

found in dry evergreen forest, riverine forest, and woodland ranging an altitude from 900 -2800 m. It is found in wide distribution in Ethiopia, Kenya, Tanzania, and Uganda. It provides multiple uses (Kelbessa and Soromessa 2008) such as edible fruits (Sina and Degu 2015), fuelwood and traditional medicine and ecological services such as shade or shelter from the leaf litter enriches underlying soil, fencing, and construction(Kebebew and Mohamed 2017).

\subsection{Sampling design}


The four tree species were selected purposively while 103 sampled trees were collected in the random sampling method. To obtain the representative tree samples, diameter distributions were taken into account during tree selection despite the stratification of diameter size varies in different studies (Kuyah et al. 2012). The overall DBH distributions and number of individual trees in the three classes were 5-15, 15 individual trees; $15-25,8$ individual trees and $25-35$ $\mathrm{cm}$, three individual trees, respectively. These numbers of the harvested individual trees were decreased as increasing diameter size because sampled trees occurred rarely as increasing diameter size in the forest. The study employed a semi-destructive technique to collect biomass data in the field and laboratory analysis following "Manual for building tree volume and biomass allometric equations" prepared by Food and Agriculture Organization (FAO) (Picard et al. 2012). During harvesting, only the small branches ranging diameter from three to $6.5 \mathrm{~cm}$ (Picard et al. 2012) were trimmed and their diameters were measured using a caliper.

\subsection{Data collection}

We measured stem diameter at breast height $(\mathrm{DBH})$ of $\geq 5 \mathrm{~cm}$ and a total height of 103 sampled trees belonging to E. cymosa Thonn. (26 individual trees), L. volkensii (Gilrke) Leroy (26 individual trees), R. urcelliformis (Hiern) Robyns (26 individual trees) and T. nobilis Del. (25 individual trees) during May 2018. The DBH and height of each sampled tree were measured using diameter tape and clinometers, respectively. A total of 78 sampled trees were harvested for three species (26 individuals for each species) using semi-destructive method, in which it was possible to complete a suitable diameter range while 25 individual trees (diameter $5-30 \mathrm{~cm}$ ) were for T. nobilis. A similar approaches of a sample size (20 individual trees) to the present study were harvested to develop allometric equations in Chilimo forest (Tesfaye et al. 2016) and 25 individuals of $J$. procera Hochst and 14 individuals of $A$. abyssinica Hochst. ex Benth in dry forests of Ethiopia (Solomon et al. 2017). During data collection, diameters of the trunk and large branches were measured at every $1 \mathrm{~m}$ length directly in the field. The basal diameters of all small branches were also measured using caliper directly in the field.

\section{Measuring trimmed and untrimmed fresh biomass}

The fresh biomass measurement (in $\mathrm{kg}$ ) was partitioned into two parts: trimmed and untrimmed fresh biomass. The fresh biomass of trimmed branches was directly measured in the field. The 
subsamples (wood aliquots) were cut at random from the trimmed branches to determine dry content of trees. Their fresh weights were measured without debarking ( $B$ aliquot fresh wood in $\mathrm{g}$ ) in the field, immediately after cutting and then they were sealed in the plastic bag, labeled and transported to the laboratory. In the similar manner, subsamples of fresh trimmed leaves and fruits were randomly composited from three different branches to constitute the aliquots. Subsamples of $200 \mathrm{~g}$ of fresh leaves in each component were measured using a digital balance and recorded their fresh weight in the field. Then, the subsamples were sealed in the plastic bag, labeled and transported for dry weight determination in the laboratory. The fresh biomass of small-untrimmed branches was calculated based on the relationship between basal diameter and dry biomass of trimmed branches. The tree sections were considered to be cylinder; whereas, density was considered to be the same for all compartments of the tree. The assumption is that along every $1 \mathrm{~m}$ length of a tree there is no tapering and every section is considered to have cylinder shape. A $0.15 \mathrm{~m}$ length of wood aliquots were harvested to determine volume and biomass because the $0.5-1 \mathrm{~m}$ for large trees and shorter lengths are recommended for smaller trees (Newton 2007). Thus, the Smalian's formula was used to calculate the volume in one-meter length of logs of trees (Picard et al. 2012).

\section{Laboratory analysis and biomass calculations}

All subsamples of wood aliquots and leaves collected from the field were transported and stored in the laboratory. We measured volumes of fresh wood aliquots (in $\mathrm{cm}^{3}$ ) using the water displacement method with a $1000 \mathrm{ml}$ measuring cylinder. Each wood aliquot was entirely merged in the water using a thin wire of negligible volume and recorded their values. To remove moisture content and determine dry matter, the wood aliquots and leaves were sealed by aluminum foil and placed in the oven at an adjusted temperature of $105^{\circ} \mathrm{C}$ and $70^{\circ} \mathrm{C}$, respectively (Picard et al. 2012). The three control aliquot samples were weighed every day for all sample categories until a constant weight is reached to avoid withdrawing actual samples from the oven for daily controls. The dried wood and leaf aliquot were measured after one week and two days, respectively to stabilize the condition. Then, we measured the dry wood and leaf aliquot using an electronic balance and recorded their values in the data sheet. The aboveground biomass (AGB, in $\mathrm{kg}$ ) of the whole tree was calculated as the sum of the dry biomass of all compartments such 
as stem, branches and leaves. The components of trimmed dry biomass were aliquots of leaf and wood. For each sample i of leaves taken, the moisture content (MC) was calculated:

MC leaf, $\mathrm{i}=\underline{B \text { aliquot dry leaf, } i}$

$B$ aliquot fresh leaf, $i$

where $B$ aliquot dry leaf, $i$ is the oven-dry biomass of the leaves in sample $i$ and $B$ aliquot fresh leaf, $i$ is the fresh biomass of leaves in the sample, $i$.

The moisture content of the wood (including bark, MC) was obtained from the ratio of fresh biomass (B) aliquot of a wood and its dry biomass (B) aliquot dry wood.

MC wood, $\mathrm{i}=\underline{B \text { aliquot dry wood, } i}$

$B$ aliquot fresh wood, $i$

where $B$ aliquot dry wood, $i$ is the oven-dry biomass of the wood in sample $i$ and $B$ aliquot fresh wood, $i$ is the fresh biomass of wood in the sample, $\mathrm{i}$. Then, the trimmed dry biomass (TDB) was obtained as:

$\mathrm{TDB}=B$ trimmed fresh wood $\times \mathrm{MC}$ wood $+B$ trimmed fresh leaf $\times$ MC leaf--------

where $B$ trimmed fresh leaf is the fresh biomass of the leaves collected from the trimmed branches and $B$ trimmed fresh wood is the fresh biomass of the wood harvested as subsample from the trimmed branches.

The dry biomass of the untrimmed part composed of three sections such as the biomass of small branches, the large branches, and the trunk. The untrimmed biomass was the sum of the two results:

$B$ untrimmed dry $=B$ untrimmed dry branch $+B$ dry section

The Smalian's formula was used to calculate each section $i$ of the trunk and the large branches as follows (Picard et al. 2012):

$$
\mathrm{Vi}=\underline{\pi \times \mathrm{Li}}\left(\mathrm{D}_{1}{ }^{2} \mathrm{i}+\mathrm{D}^{2}{ }_{2} \mathrm{i}\right)
$$

\section{8}

where $\mathrm{Vi}$ is the volume of section $i, L i$ is length of one meter $\log$ of trees, and $D_{1} i$ and $D_{2} i$ are the diameters of the two extremities of section $i$.

The dry biomass of the large branches and trunk was calculated as the product of mean wood density (WD) and total volume as follows: 
$B$ dry section $=\mathrm{WD} \times \sum_{\mathrm{i}} \mathrm{V}$

where the value of $V i$ was from Smalian's formula and the sum corresponds to all the sections in the large branches and the trunk, and mean wood density (WD) was calculated by:

$$
\begin{gathered}
\mathrm{WD}=\underline{B \text { aliquot dry wood }} \\
\mathrm{V} \text { aliquot fresh wood }
\end{gathered}
$$

Therefore, the dry biomass of trunk and larger branches was estimated from their calculated volume $\left(\mathrm{m}^{3}\right)$ and the mean wood density $\left(\mathrm{g} \mathrm{m}^{-3}\right)$ of the respective tree species.

The model between dry biomass and basal diameter was used to calculate the dry biomass of the untrimmed small branches (Picard et al., 2012) as:

$$
B \text { dry branch }=a+b D i^{c}
$$

where $a, b$ and $c$ are model parameters and $D i$ is basal diameter of the branch i. Using a model of this type, the dry biomass of the untrimmed branches was:

$$
B \text { untrimmed dry small branch }=\sum_{\mathrm{i}}\left(\mathrm{a}+\mathrm{bDi}^{\mathrm{c}}\right)
$$

where the sum was all the untrimmed small branches and $D i$ is the basal diameter of the branch $i$.

\section{Model construction}

The allometric models were constructed on the base of measured dendrometric variables such as the diameter at breast height (DBH, in $\mathrm{cm}$ ), height ( $\mathrm{H}$ in $\mathrm{m}$ ) and wood density (WD in $\mathrm{g} \mathrm{cm}^{-3}$ ) as predictors and total aboveground biomass (AGB) of trees as the response variable. The normality test for the model development was performed by Shapiro-Wilk test to examine whether the residual of the data set was normally distributed or not. Then, if the data did not fit normality, the logarithmic transformation was used to satisfy the normality of residuals and homogeneity of variances (Xiao et al. 2011; Djomo et al. 2016). Since logarithmic transformation of the variables results in a systematic bias, back-transformed AGB estimates were multiplied by the correction factor $(\mathrm{CF})=\exp \left(\mathrm{RSE}^{2} / 2\right)$ where RSE is the residual standard error. The diameter was first tested as an independent variable to develop the allometric equations and subsequently height and wood density was performed stepwise as follows:

$$
\begin{aligned}
& \text { 1. } \mathrm{AGB}=\exp \left[\alpha+\beta_{0} \ln (\mathrm{DBH})\right] \\
& \text { 2. } \mathrm{AGB}=\exp \left[\alpha+\beta_{0} \ln (\mathrm{DBH})+\beta_{1} \ln (\mathrm{H})\right] \\
& \text { 3. } \mathrm{AGB}=\exp \left[\alpha+\beta_{0} \ln (\mathrm{DBH})+\beta_{1} \ln (\mathrm{H})+\beta_{2} \ln (\mathrm{WD})\right]
\end{aligned}
$$


where AGB (in $\mathrm{kg}$ ) is total aboveground biomass of trees as response and DBH is diameter at breast height $(\mathrm{cm}), \mathrm{H}$ is height $(\mathrm{m})$ and $\mathrm{WD}$ is wood density $\left(\mathrm{g} \mathrm{cm}^{3}\right)$ as independent variables, exp is exponential, ln is natural logarithmic, $\alpha$ is intercept and $\beta_{\mathrm{o}}, \beta_{1}$ and $\beta_{2}$ are estimators.

\subsection{Data analysis and model selection}

The statistical analysis was conducted with $\mathrm{R}$ statistical software and decided at a significant level $(\alpha)$ of 0.05 . Based on data collected and laboratory analyses, many allometric models were constructed for AGB estimations against predictors. The model selection and validation was based on statistical significance of model parameter estimates, Akaike Information Criterion (AIC), adjusted coefficient of determination (adj. $\mathrm{R}^{2}$ ), residual standard error (RSE) and mean relative error (MRE) (Chave et al. 2005). Akaike information criterion (AIC):

$$
\mathrm{AIC}=2 \mathrm{p}-2 \ln (\mathrm{L})
$$

where $\mathrm{L}$ is the likelihood of the fitted model, $\mathrm{p}$ is the total number of parameters in the model and $\ln$ is natural logarithmic. The regression equation with the lowest AIC value is the best estimator.

adj. $\mathrm{R}^{2}$ value indicates the total variation of the data explained by the validated equations. It is between 0 and 1 , and the closer it is to 1 , the better the quality of the fit. This was calculated as:

$$
\text { adj. } R^{2}=\left[1-\frac{\sum_{\mathrm{i}=1}^{\mathrm{n}}(\text { AGBesti }- \text { AGBobs })^{2}}{\sum_{\mathrm{i}=1}^{\mathrm{n}}(\text { AGBobs }- \text { mAGBobs }) 2}\right]
$$

where AGB esti is the estimated aboveground biomass in $\mathrm{kg}$; AGB obs is the observed aboveground biomass in $\mathrm{kg}$ and $\mathrm{mAGB}$ obs is the mean observed individual biomass in $\mathrm{kg}$. To measure total error or residual standard error, it was computed the coefficient of variation in AGB as:

$$
\mathrm{RSE}=\sqrt{\sum_{\mathrm{i}=1}^{\mathrm{n} \frac{(\text { AGBesti }- \text { AGBobs }) 2}{\mathrm{n}-\mathrm{p}}}}
$$

where RSE is the residual standard error, AGB esti is the estimated aboveground biomass in $\mathrm{kg}$; AGB obs is the observed aboveground biomass in $\mathrm{kg} ; \mathrm{n}$ is the number of sampled trees; and, $\mathrm{p}$ is the number of parameters in the model. The larger the RSE, the more uncertain regression models to predict biomass.

The mean relative error (MRE) and root mean squared error (RMSE) were calculated for validation criteria of model performance. They were calculated after the predictions were backtransformed to the unit values. It was computed to test model validations as follows: 
$\operatorname{MRE}(\%)=\frac{100}{\mathrm{n}} \sum_{\mathrm{i}=1}^{\mathrm{n}}\left(\frac{\mathrm{AGB} \text { esti }- \text { AGB obs }}{\text { AGB obs }}\right)$

where AGB esti and AGB obs are aboveground biomass estimated and observed respectively, $\mathrm{n}$ $=$ number of sampled trees.

The root mean squared error (RMSE) was calculated to validate variation of estimated AGB from observed AGB as follows:

$$
\mathrm{RMSE}=\sqrt{\frac{1}{\mathrm{n}} \sum_{\mathrm{i}=1}^{\mathrm{n}}\left(\frac{\mathrm{AGB} \text { esti }- \text { AGB obs }}{\mathrm{AGB} \text { obs }}\right)^{2}}
$$

Where AGB esti and AGB obs are the estimated and observed aboveground biomass, respectively, and $\mathrm{n}$ is the total number of trees.

A total of 60 allometric models (15 models for each tree species) were tested and about 10 models for each species were selected with adj. $R^{2} \geq 70 \%$ for this study. Therefore, the highest adjusted $\mathrm{R}^{2}$ value but small RSE and AIC were considered for model selection (Djomo et al. 2016). These models were the most common for allometry development (Brown et al. 1989; Chave et al. 2005; Chave et al. 2014). The adj. $\mathrm{R}^{2}$ was used to evaluate model fitted while model prediction errors were assessed by MRE (\%) and RMSE. The differences between the measured and estimated AGB were analyzed by paired T-test. The tree biomass estimations using speciesspecific allometric equations were also compared with tree biomass estimations of general allometric equations and the differences were examined using paired $\mathrm{T}$ test. The choice of existing general allometric equations depend on the forest type and these are AGB = exp ($\left.2.4090+0.9522 \ln \left(\mathrm{WD} \mathrm{DBH}^{2} \mathrm{H}\right)\right)($ Brown et al. 1989); $\mathrm{AGB}=\exp (-2.187+0.916 \ln (\mathrm{WD}$ $\left.\left.\mathrm{DBH}^{2} \mathrm{H}\right)\right)\left(\right.$ Chave et al. 2005)) and $\mathrm{AGB}=0.0673 \times\left(\mathrm{WD} \mathrm{DBH}^{2} \mathrm{H}\right)^{0.976}($ Chave et al. 2014)).

\section{Results}

\subsection{Predictors and measured aboveground biomass}

The results revealed that the aboveground biomass varied among components and species as shown in Table 1. The mean aboveground biomass ranged from $68.23 \pm 10.00 \mathrm{~kg}$ for L. volkensii to $119.40 \pm 26.00 \mathrm{~kg}$ for $R$. urcelliformis. Such biomass variations were also observed between tree components like trunk (22.8 to $41.3 \%)$ and large branches (22.9 to $34.2 \%)$. The dendrometric variables including the height $(\mathrm{H}, \mathrm{m})$, diameter $(\mathrm{DBH}, \mathrm{cm})$, woody density $(\mathrm{WD}, \mathrm{g}$ $\mathrm{cm}^{-3}$ ) varied per species (Table 1 and Table S1). The harvested individual trees showed a variety 
of diameters, from 5 to $35 \mathrm{~cm}$, and different heights, ranging from 4 to $16 \mathrm{~m}$. This result revealed the existence of growth differences among individual species that might become the source of biomass variations of forests. The mean diameter of $T$. nobilis $(13.53 \pm 1.34 \mathrm{~cm})$ and $R$. urcelliformis $(14.89 \pm 1.48 \mathrm{~cm})$ accounted for the lowest and highest diameters, respectively. The mean height ranged from $8.25 \pm 0.63$ to $9.30 \pm 0.67 \mathrm{~m}$ in T. nobilis and E. cymosa, respectively. The results of dry matter analysis showed that the woody density also varied among species, ranging from 0.438 to $0.632 \mathrm{~g} \mathrm{~cm}^{-3}$, with the lowest and highest exhibited by E. cymosa and T. nobilis, respectively. Such variations were also noticed within the individuals of sampled trees. Similarly, the values of Smalian's volume of the species ranged from $0.065 \pm 0.008$ to $0.097 \pm 0.024 \mathrm{~m}^{3}$, with the lowest and highest in E. cymosa and T. nobilis, respectively.

\subsection{Aboveground biomass and its relation with dendrometric values}

The results showed that the AGB correlated significantly with the diameter at breast height $\left(\mathrm{R}^{2}>\right.$ 0.944; $\mathrm{P}<0.001$ ) (Fig. 2A1-D1) and tree height $\left(\mathrm{R}^{2}>0.742, \mathrm{P}<0.001\right.$ (Fig. 2 A2-D2). Out of studied species, the AGB strongly correlated with the DBH $\left(\mathrm{R}^{2}=0.981, \mathrm{P}<0.001\right)$ and height $\left(\mathrm{R}^{2}=0.902, \mathrm{P}<0.001\right)$ of $T$. nobilis. However, AGB was not significantly correlated with the wood density of E. cymosa $\left(\mathrm{R}^{2}=0.042, \mathrm{P}>0.05\right)$, L. volkensii $\left(\mathrm{R}^{2}=0.015, \mathrm{P}>0.05\right), R$. urcelliformis $\left(\mathrm{R}^{2}=0.039, \mathrm{P}>0.05\right)$ and T. nobilis $\left(\mathrm{R}^{2}=0.217, \mathrm{P}>0.05\right)$. Although the wood density was not significantly correlated with the AGB, it was included in the model testing because it varied considerably among tree species.

\subsection{Allometric equations and their performance}

Allometric equations relating response variable (total aboveground biomass, AGB) against predictors (i.e. DBH, H, and WD) were formulated for E. cymosa, L. volkensii, R. urcelliformis

and T. nobilis. The accuracy of allometric equations for AGB estimations was good based on model performance statistics as shown the descriptive summary in Table 2 and 3. The AGB correlated significantly with the predictors in high adj. $\mathrm{R}^{2}$ ranging between 0.691 and 0.940 of which all selected models had high model fit $\left(\operatorname{adj} . \mathrm{R}^{2} \geq 0.936, \mathrm{P}<0.001\right)$ and relatively low values of the residual standard error (RSE). The inclusion of all three predictors explained the best allometric models to estimate biomass. The diameter at breast height and total height appeared the most frequent parameters across all equations to estimate biomass. In comparison, 
the diameter as a single parameter predicted better AGB with a lower MRE $(<4.0 \%)$ than the height as a single predictor (MRE > 5.0\%) of the four studied species. The allometric equations and their model performance for AGB of studied species are explained as follows:

\section{Ehretia cymosa Thonn.}

The result revealed that the adj. $\mathrm{R}^{2}$ in ten models (Ehretia cymosa, ECM1- ECM10) ranged between 70.7 and $94.0 \%$ with an average ( \pm standard deviation) of $90.1 \%$ (6.9\%), showing a best explanation of biomass variations (Table 2). The range of statistical selection parameters values varied in constructed models $(\mathrm{RSE}=0.247$ and 0.550$)$ and $(\mathrm{AIC}=5.43$ and 46.63). The mean relative errors (MRE) ranged between 2.6 and 14.2\%, substantially lower the value of ECM1 and the higher of ECM10, respectively. When the three independent variables (DBH, H and WD) combined in the ECM1, they improved the quality of the AGB prediction with a lower value of MRE (2.6\%), RSE (0.247), AIC (7.76) and the highest adj.R ${ }^{2}$ (94.0\%). This allometric equation was:

$$
\mathrm{AGB}=\exp [-1.137+2.129 \ln (\mathrm{DBH})-0.035 \ln (\mathrm{H})+0.460 \ln (\mathrm{WD})] .
$$

The second allometric equation (ECM2) can be applied for biomass estimation when the height and wood density of a species will not be available. This model used a single parameter of diameter with a lower value of AIC (5.43), RSE (0.249) and MRE (2.8\%) and the highest adj. $\mathrm{R}^{2}$ (93.9\%). The simple allometric equation was:

$$
\mathrm{AGB}=\exp [-1.662+2.155 \ln (\mathrm{DBH})] .
$$

The third allometric equation (ECM3) showed that the AGB did not depend on wood density $(\beta 2=0)$. The combination of diameter and height predicted the AGB with a lower value of AIC (7.40), RSE (0.252) and MRE (2.7\%) and the highest adj. $\mathrm{R}^{2}(93.8 \%)$. This allometric equation was:

$$
\mathrm{AGB}=\exp [-1.624+2.188 \ln (\mathrm{DBH})-0.057 \ln (\mathrm{H})]
$$

\section{Lepidotrichilia volkensii (Gürke) J.-F.Leroy}

The result showed that the adj. $\mathrm{R}^{2}$ in ten allometric equations explained in the highest model fit ranging from $76.9-93.9 \%$ of biomass variations, which were an average ( \pm standard deviation) of $89.1 \%(5.3 \%)$ (Table 2). The best allometric model (Lepidotrichilia volkensii, (LVM1) for AGB estimation obtained from the combination of diameter, height, and wood density. This 
model substantially improved the accuracy of the estimates $(\mathrm{MRE}=1.50 \%)$ and $\left(\operatorname{adj} \cdot \mathrm{R}^{2}=\right.$ 93.9\%). It can be the best allometric model to estimate AGB when all three variables will be available as:

$$
\mathrm{AGB}=\exp [-0.040+1.758 \ln (\mathrm{DBH})-0.094 \ln (\mathrm{H})+0.519 \ln (\mathrm{WD})] .
$$

This equation gives the best fit with three variables with an RSE of 0.173 , an adj. $\mathrm{R}^{2}$ of 0.939 and an AIC of - 11.84. The other allometric model (LVM3) can be used to estimate the AGB when the height and wood density of tree will not be available. The AGB can be related with a diameter as:

$$
\mathrm{AGB}=\exp [-0.255+1.638 \ln (\mathrm{DBH})]
$$

\section{Rothmannia urcelliformis (Hiern) Bullock ex Robyns}

The result revealed that the ten species-specific allometric models explained by adj. $\mathrm{R}^{2}$ were an average ( \pm standard deviation) 89.6\% (7.0\%) (Table 3). The combination of diameter, height and wood density in the Rothmannia urcelliformis (RUM) 1 predicted better the total biomass of $R$. urcelliformis (adj. $\mathrm{R}^{2}=0.936, \mathrm{AIC}=10.21, \mathrm{RSE}=0.278$ and $\mathrm{MRE}=3.4 \%$ ). This allometry relating the AGB against the predictors was:

$$
\mathrm{AGB}=\exp [-2.309+2.289 \ln (\mathrm{DBH})+0.019(\mathrm{H})-0.937 \ln (\mathrm{WD})]
$$

In comparison with RUM1, RUM2 can be the best allometric model to estimate the biomass of species when height and wood density will not be available. The simple allometry relating the AGB against a diameter was:

$$
\mathrm{AGB}=\exp [-1.591+2.249 \ln (\mathrm{DBH})]
$$

\section{Teclea nobilis Del.}

The result showed that the ten allometric equations generally fit, ranging from 79.3 to $94.2 \%$ (adj. $\mathrm{R}^{2}$ ) of the observed biomass variations (Table 3 ). The total variance explained by the models was an average ( \pm standard deviation) of $90.4 \%$ (4.7\%) and the RSE values ranged from 0.241 to 0.453 . The combination of diameter, height and wood density in model construction of Teclea nobilis (TNM1) estimated AGB with a lower value of MRE (2.6\%) than TNM2 (3.2\%). Therefore, when compared to the models using a diameter as a single predictor, the inclusion of both height and wood density improved the AGB prediction. The allometry relating AGB against the predictors was:

$$
\mathrm{AGB}=\exp [-1.290+1.667 \ln (\mathrm{DBH})+0.397 \ln (\mathrm{H})-0.639 \ln (\mathrm{WD})]
$$


The allometric model using the diameter as a predictor accounted for $93.8 \%$ of adj. $\mathrm{R}^{2}$ in the AGB estimation of $T$. nobilis. It can be the best allometric model (TNM2) to estimate total biomass with MRE of $3.2 \%$ when the height and wood density will not be available. This allometry model estimated the AGB using a diameter as predictor as follows:

$$
\mathrm{AGB}=\exp [-1.186+2.068 \ln (\mathrm{DBH})] .
$$

The allometric model (TNM4) including only the diameter and height explained 93.9\% of AGB variation by coefficient of determination and $(\mathrm{RSE}=0.245, \mathrm{P}<0.001)$. AGB can be estimated using the allometry as:

$$
\mathrm{AGB}=\exp [-1.252+1.798 \ln (\mathrm{DBH})+0.364 \ln (\mathrm{H})]
$$

On the contrary, the height of tree estimated AGB less model efficient (adj. $\mathrm{R}^{2}=79.3 \%$ ) than the diameter.

\subsection{Linear relation between the measured and predicted aboveground biomass}

Results of the validation analysis for the modeling AGB are presented in Figures 3A - D. The validation of AGB predictions by developed models showed linear relation against measured AGB in all species with high model fit $\left(\operatorname{adj} . \mathrm{R}^{2} \geq 0.902, \mathrm{P}<0.001\right)$. Based on the 1:1 relationship between the observed and predicted AGB for the validation data set, the developed models predict equally well and are not too far from the baseline and showed less scattered plot. The relative errors of estimated averages from observed average AGB per tree ranged from 1.50$3.40 \%$ (Table 2 and 3). This suggested that the AGB estimations using species-specific allometric models in this study tended to show a non-significant bias.

\subsection{Model comparison with existing allometric equations}

The result showed that the AGB estimations of E. cymosa, R.urcelliformis, T. nobilis and L.volkensi by general allometric models (GAM) had shown 7.72 .44 to $19.24 \%, 41.44$ to $50.77 \%$, 5.07 to $5.92 \%$ and 30 to $43 \%$ of variations from measured AGB, respectively. The mean relative error (bias) in the AGB estimation by the general models resulted in wider ranges from - 31.3 to $11.31 \%$ than that of the presently constructed models (1.46 to $3.44 \%$ (Table 4 ). The estimation of AGB by general allometric models tended to show the higher root mean squared error (RMSE $\geq 26.753)$ than the species-specific allometric models (RMSE $\leq 26.345)$ in all studied species. In 
the comparison, species-specific allometric model (SSAM) predicted the AGB of L. volkensi with the smaller RMSE $=12.928$ than the general allometric model of Chave 2005 (RMSE $\geq$ 62.322). The paired T-test comparison showed that the AGB estimates of $R$. urcelliformis based on general equations were significantly different from measured AGB at $\mathrm{P}<0.05$. This indicates the need to develop species-specific allometric models for accurate biomass estimations.

\section{Discussion}

The species-specific allometric models were constructed and the relationship between the AGB and dendrometric variables such as $\mathrm{DBH}, \mathrm{H}$ and WD of studied species were tested for dry Afromontane trees. The AGB estimations against combination of these variables in the speciesspecific allometric model showed the best model performance. The developed models related AGB against predictors in the $\log -\log$ forms and these model relationships between AGB and predictors was the best in terms of goodness of fits. These findings are in good agreement with those of previous studies, which demonstrated the advantage of the log-log models for the prediction of tree biomass (Chave et al. 2005; Djomo et al. 2010; Chave et al. 2014). Other previous study on tree biomass showed that a power model allows a good estimation of aboveground biomass of trees (Vieilledent et al. 2012). However, a power model might be unsuitable model in this study because raw data (Appendix Table S1) of AGB predictors exhibited non-normal distributions ( $p$-values of Shapiro-Wilk < 0.05).

Studies have shown that the height-diameter relationship varies significantly with climate (Banin et al. 2012); soil fertility (Soong et al. 2020) and climatic zones (Nogueira et al. 2007), forest types and region (Banin et al. 2012). As such, the same tree species growing in different sites might have different biomass in the forests. Since climate variation and soil fertility affects tree growth (Soong et al. 2020), the inclusion of the tree height in developing allometric models improves the accuracy of biomass estimations of forests. The relation between DBH and AGB demonstrates a high coefficient of determination in the linear regression. This indicates that the diameter of trees accounts for most of the biomass variation observed. In comparison of predictors, diameter at breast height was a more reliable predictor than height and wood density. Several biomass equations have been published relating tree biomass to the diameter and they have shown a high model performance between these variables (Brown et al. 1989; Chave et al. 
2005; Chave et al. 2014). The reason behind the strong relation between DBH and AGB might be due to the easiest variable to measure the diameter of trees in the field. However, considering tree heights in the present study improve the species-specific allometric models efficiency and reduce uncertainty in AGB estimations. The inclusion of wood density in the species-specific allometric models also demonstrates an important to complement biomass estimations because the wood density values of species varied across climatic condition and soil fertility as indicated in the previous wood density database (Zanne et al. 2013). In addition, Ethiopian forest reference level (EFRL 2016) reported that the previously studies did not determine the wood density values of those studied species using oven dry matter analysis at the species level. Therefore, the wood density values of studied species can also be useful to complement biomass estimations in the general allometric equations. For instance, the importance of including tree height and wood density in biomass estimation of E. cymosa and $R$. urcelliformis had shown the best evidence. $E$. cymosa stores a mean AGB of $69.11 \pm 13.9 \mathrm{~kg}$, whereas $R$. urcelliformis contains a higher mean AGB of $119.4 \pm 26.036 \mathrm{~kg}$. The differences in wood density and tree structures possible explain the differences in the AGB of these two species. Although E. cymosa has a smaller diameter and wood density than L. volkensi, it has a higher height compared to that of L. volkensi, resulting in the small AGB variation between them. Therefore, it is important to include height as an explanatory variable in AGB models to minimize variation generated by environmental factors.

In relation to the allometric models, the result showed that including diameter, height and wood density as input variables estimated accurately aboveground biomass of trees. This result agreed with the previous studies that the combination of three predictors in the species-specific allometric equations provided an accurate biomass estimation in mixed-species forests (Henry et al. 2010; Djomo et al. 2010; Vieilledent et al. 2012; Chave et al. 2014; Djomo et al. 2016). In agreement of previous studies, the species-specific allometric models will be applicable to biomass estimations in the dry tropical forests. Despite the fact that many studies confirmed on the importance of dendrometric variables to estimate biomass, there are arguments on the potential of predictor variables like height and wood density. Some studies found that the inclusion of height (Kuyah et al. 2012; Solomon et al. 2017; Tetemke et al. 2019) did not improve the accuracy of models to estimate biomass. In contrast, other previous studies confirmed that the inclusion of tree height improves the accuracy of models (Mokria et al. 2018). In the similar manner, there are disagreements on the potential of wood density to predict 
aboveground biomass. Some previous studies revealed that the inclusion of wood density improves accuracy of biomass estimations (Kuyah et al. 2012). Despite the fact that scientific studies did not find general agreement on the potential of dendrometric variables particularly the inclusion of height and wood density to estimate biomass, it is better to consider variations of tree heights within a species and adaptability potential of wood density in response to environmental stress and forest types. These factors might lead to biomass variations of forests; and thus needed the inclusion of height and wood density for biomass estimations.

Aboveground biomass distribution varied among trees and their components. The stems and branches of trees consisted of the largest portions of biomass. These biomass portions among components of studied species agreed with the previous studies as they have reported greater proportion (> 65\%) of biomass allocated in stem wood (Henry et al. 2010; Ebuy et al. 2011; Djomo et al. 2010). These different biomass fractions may be expected depending on dendrometric values of trees (Archibald and Bond 2003). The accuracy in biomass estimation largely depends on the appropriate selection of allometric models on the base of model performance statistical values. In this study, the fitted model in the allometric equation represents best biomass predictor because the total variation explained by the coefficient of determination (adj. $\mathrm{R}^{2}$ ) was above 0.90 compared to the recommended value (0.85) (UNFCCC 2011). The residual standard errors of most selected models in this study also retained lower than the reference level (RSE < 0.25) (Sileshi 2014), which could result in realistic biomass estimation by using these models. Hence, these models might be higher statistically reliable for future use.

Many studies showed dry tropical allometric equations for large-scale biomass estimations (Brown et al. 1989; Chave et al. 2005; Chave et al. 2014). Their equations have been widely used in dry tropical forests in areas where no species-specific equations for biomass estimations were developed. In fact, the study found significant differences in biomass estimates in some studied species when using species-specific compared to generic allometric equations. The presently developed allometric equations remained the lowest bias (ranging from 1.46 to $3.44 \%$ ) in the biomass prediction than that of general equations (ranging -31.3 to $11.31 \%$ ). Similar to the present study, the previous studies found small bias in species-specific equations compared to general models (Nelson et al. 1999). Although the selected general biomass model performed well globally, the species-specific AGB models performed far better than the generalized models 
with small bias. The generalized models greatly tended to overestimate biomass and show difference between measured and predicted AGB as increasing the diameter of trees (Brown et al. 1989; Chave et al. 2005; Chave et al. 2014). The paired t-test also showed that the means of the measured AGB were slightly different from the predicted AGB values using the general models. However, the means of measured AGB did not show a significant difference with predicted AGB by the species-specific allometric models and the better agreement between measured AGB and dendrometric variables. This result provides an insight into the potential of local models for the accurate biomass estimations.

\section{Conclusions}

The result revealed that the inclusion of diameter, height and wood density in the development of species-specific allometric equations predicted aboveground biomass with small bias than using a single or two predictors. These developed equations can be used for the biomass estimations of trees in the diameter range of 5-35 cm. Thus, the best selected allometric equations of this study showed higher model fit for biomass estimations compared to some frequently used general allometric equations. The wood density values of those studied species can be used as the references for biomass estimations using general allometric equations. The study also contributes to species-specific allometric models for understanding the total biomass estimation of studied species. Therefore, the application of species based allometric models should be considered for the accurate biomass estimations and to enhance carbon sequestration of tropical forests.

\section{Abbreviations}

SSAM: Species-specific Allometric Model

AGB: Aboveground Biomass

DBH: Diameter at Beast Height

H: Height

WD: Wood Density

$\mathrm{R}^{2}$ : Multiple Correlations

adj. $\mathrm{R}^{2}$ : Adjusted Coefficient of Determination

AIC: Akaike Information Criterion

RSE: Residual Standard Error 
MRE: Mean Relative Error

MC: Moisture Content

TDB: Trimmed Dry Biomass

B: Biomass

Vi: Smalian's Volume of Section

Li: Length of Section

V: Volume of Aliquot Fresh Wood

Di: Basal Diameter

CF: Correction Factor

RSE: Residual Standard Error

AGB esti: Estimated Aboveground Biomass;

AGB obs: Observed Aboveground Biomass

mAGB: Mean Observed Aboveground Biomass

RMSE: Root Means Squared Error

ECM: Ehretia cymosa Biomass Model

LVM: Lepidotrichilia volkensii Biomass Model

RUM: Rothmannia urcelliformis Biomass Model

TNM: Teclea nobilis Biomass Model

GAM: General Allometric Model

\section{Declarations}

Ethics approval and consent to participate

Not applicable

\section{Consent for publication}

Not applicable

\section{Availability of data and materials}

All data for this study are included in supplementary information file (Table S1).

\section{Competing interests}

The authors declare that they have no competing interests. 


\section{Funding}

None

\section{Author contributions}

Getaneh Gebeyehu conceived the idea and performed data collection in the field, laboratory analysis, and wrote up draft the manuscript. Teshome Soromessa suggested the need for development of models for studied species and supervised the research work in all stages. Tesfaye Bekele supported data collection in the field. Demel Teketay critically reviewed draft manuscript.

\section{Acknowledgments}

We are grateful to Addis Ababa University (AAU) and Ethiopian Environment and Forestry Research Institute (EERIE) for financial support. We also thank Awi agricultural office and field assistants who gave us valuable support in the permission of destructive harvesting and the fieldwork.

\section{Authors' information}

${ }^{1}$ Getaneh Gebeyehu, Biology Department at Assosa University, Assosa, Ethiopia. ${ }^{2}$ Teshome Soromessa, Center for Environmental Science, College of Science at Addis Ababa University, Addis Ababa, Ethiopia. ${ }^{3}$ Tesfaye Bekele, Ethiopian Environment and Forestry Research Institute, Addis Ababa, Ethiopia.

${ }^{4}$ Demel Teketay, Botswana University of Agriculture and Natural Resources, Gaborone, Botswana.

References

Addis G, Asfaw Z, Woldu Z (2013) The role of wild and semi-wild edible plants to household food sovereignty in Hamar and Konso communities, South Ethiopia. Ethnobotany Research and Applications 11: 251-271.

Archibald S, Bond WJ (2003) Growing tall vs growing wide: tree architecture and allometry of Acacia karroo in forest, savanna, and arid environments. Oikos 102: 3-14.

Banin L, Feldpausch T, Phillips O, Baker T, Lloyd J, Affum-Baffoe K, Arets E, Berry N, Bradford M, Brienen R (2012) What controls tropical forest architecture? Testing environmental, structural and floristic drivers. Global Ecol Biog 21: 1179-1190.

Brown S (2002) Measuring carbon in forests: current status and future challenges. Environmental pollution 116: 363-372. 
Brown S, Gillespie AJ, Lugo AE (1989) Biomass estimation methods for tropical forests with applications to forest inventory data. Forest Sci 35:881-902.

Chave J, Réjou-Méchain M, Búrquez A, Chidumayo E, Colgan MS, Delitti WB, Duque A, Eid T, Fearnside PM, Goodman RC (2014) Improved allometric models to estimate the aboveground biomass of tropical trees. Global Chan Biol 20:3177-3190.

Chave JR, Andalo C, Brown S, Cairns MA, Chambers J, Eamus D, Fölster H, Fromard F, Higuchi N, Kira T (2005) Tree allometry and improved estimation of carbon stocks and balance in tropical forests. Oecologia 145: 87-99.

Chojnacky DC (2002) Allometric scaling theory applied to FIA biomass estimation. In: McRoberts, Ronald E.; Reams, Gregory A.; Van Deusen, Paul C.; Moser, John W., eds. Proceedings of the Thrid Annual Forest Inventory and Analysis Symposium; Gen. Tech. Rep. NC-230. St. Paul, MN: US Department of Agriculture, Forest Service, North Central Research Station: 96-102.

Djomo AN, Ibrahima A, Saborowski J, Gravenhorst G (2010) Allometric equations for biomass estimations in Cameroon and pan moist tropical equations including biomass data from Africa. Forest Ecol Manag 260: 1873-1885.

Djomo, AN, Picard N, Fayolle A, Henry M, Ngomanda A, Ploton P, Mclellan J, Saborowski J, Adamou I, Lejeune P (2016) Tree allometry for estimation of carbon stocks in African tropical forests. Forestry:Int J Forest Res 89: 446-455.

Ebuy J, Lokombe J, Ponette Q, Sonwa D, Picard N (2011) Allometric equation for predicting aboveground biomass of three tree species. J. Trop Forest Sci 125-132.

Gakuubi MM, Wanzala W (2012) A survey of plants and plant products traditionally used in livestock health management in Buuri district, Meru County, Kenya. J Ethnob Ethnomed 8: 39.

Gebeyehu G, Soromessa T, Bekele T, Teketay D (2019) Species composition, stand structure, and regeneration status of tree species in dry Afromontane forests of Awi Zone, northwestern Ethiopia. Ecosystem Health and Sustainability 5: 1-17.

Gibbs HK, Brown S, Niles JO, Foley JA(2007) Monitoring and estimating tropical forest carbon stocks: making REDD a reality. Environ Res Lett 2: 045023.

Gina Tg, Nigatu L, Animut G (2014) Biodiversity of Indigenous Multipurpose Fodder Trees of Wolayta Zone, Southern Ethiopia: Ecological and Socio-Economic Importance. Int J Emerg Tech Adv Engin 4: 494-503.

Henry M, Besnard A, Asante W, Eshun J, Adu-Bredu S, Valentini R, Bernoux M, Saint-André L (2010) Wood density, phytomass variations within and among trees, and allometric equations in a tropical rainforest of Africa. Forest Ecol Manag 260:1375-1388.

Kebebew M, Mohamed E (2017) Indigenous knowledge on use of medicinal plants by indigenous people of Lemo district, Hadiya zone, Southern Ethiopia. Int J Herb Med 5: 124-35.

Kebede B, Soromessa T (2018) Allometric equations for aboveground biomass estimation of Olea europaea L. subsp. cuspidata in Mana Angetu Forest. Ecosystem Health and Sustainability 4: 1-12.

Kelbessa E, Soromessa T (2008) Interfaces of regeneration, structure, diversity and uses of some plant species in Bonga Forest: A reservoir for wild coffee gene pool. SINET: Ethiopian J Sci 31: 121-134. 
Kuyah S, Dietz J, Muthuri C, Jamnadass R, Mwangi P, Coe R, Neufeldt H (2012) Allometric equations for estimating biomass in agricultural landscapes: II. Belowground biomass. Agri Ecosys Environ 158: 225-234.

Mokria M, Mekuria W, Gebrekirstos A, Aynekulu E, Belay B, Gashaw T, Bräuning A (2018) Mixed-species allometric equations and estimation of aboveground biomass and carbon stocks in restoring degraded landscape in northern Ethiopia. Environ Res Lett 13: 024022.

Návar J (2009) Biomass component equations for Latin American species and groups of species. Annals of Forest Sci 66:1-21.

Nelson BW, Mesquita R, Pereira JL, De Souza SGA, Batista GT, Couto LB (1999) Allometric regressions for improved estimate of secondary forest biomass in the central Amazon. Forest Ecol Manag 117:149-167.

Neuwinger HD (1996) African ethnobotany: poisons and drugs: chemistry, pharmacology, toxicology, CRC Press.

Newton A (2007) Forest ecology and conservation: a handbook of techniques, Oxford University Press on Demand.

Nogueira EM, Fearnside PM, Nelson BW, França MB (2007) Wood density in forests of Brazil's 'arc of deforestation': Implications for biomass and flux of carbon from land-use change in Amazonia. Forest Ecol Manag 248: 119-135.

Picard N, Saint-André L, Henry M (2012) Manual for building tree volume and biomass allometric equations: from field measurement to prediction. Manual for building tree volume and biomass allometric equations: from field measurement to prediction, FAO; Food and Agricultural Organization of the United Nations.

Seta T, Demissew S, Asfaw Z (2013) Home gardens of Wolayta, Southern Ethiopia: an ethnobotanical profile. Academia J. Medicinal Plants 1: 14-30.

Sileshi GW (2014) A critical review of forest biomass estimation models, common mistakes and corrective measures. Forest Ecol Manag 329:237-254.

Sina B, Degu HD (2015) Knowledge and use of Wild Edible Plants in the Hula District of the Sidama Zone. Int J Bio-resource and Stress Manag 6: 352-365.

Solomon N, Birhane E, Tadesse T, Treydte AC, Meles K (2017) Carbon stocks and sequestration potential of dry forests under community management in Tigray, Ethiopia. Ecol Processes 6: 20.

Soong JL, Janssens IA, Grau O, Margalef O, Stahl C, Van Langenhove L, Urbina I, Chave J, Dourdain A, Ferry B (2020) Soil properties explain tree growth and mortality, but not biomass, across phosphorus-depleted tropical forests. Scientific Reports 10: 1-13.

Tesfaye MA, Bravo-Oviedo A, Bravo F, Ruiz-Peinado R (2016) Aboveground biomass equations for sustainable production of fuelwood in a native dry tropical afro-montane forest of Ethiopia. Annals of Forest Sci 73: 411-423.

Tetemke BA, Birhane E, Rannestad MM, Eid T (2019) Allometric Models for Predicting Aboveground Biomass of Trees in the Dry Afromontane Forests of Northern Ethiopia. Forests 10: 1114.

UNFCCC (2011) D. 1/CP. 17 in Report of the Conference of the Parties on its Seventeenth Session. United Nations Framework Convention on Climate Change.

Vieilledent G, Vaudry R, Andriamanohisoa SF, Rakotonarivo OS, Randrianasolo HZ, Razafindrabe HN, Rakotoarivony CB, Ebeling J, Rasamoelina M (2012) A universal 
approach to estimate biomass and carbon stock in tropical forests using generic allometric models. Ecological Applications 22: 572-583.

Worku E, Soromessa T (2015) Allometric equation for biomass determination in Juniperus procera Endl. and Podocarpus falcatus Mirb of wof-washa forest: Implication for climate change mitigation. American Journal of Life Sciences 3: 190-202.

Xiao X, White EP, Hooten MB, Durham SL (2011) On the use of log-transformation vs. nonlinear regression for analyzing biological power laws. Ecology 92:1887-1894.

Zanne A, Lopez-Gonzalez G, Coomes D, Ilic J, Jansen S, Lewis S, Miller R, Swenson N, Wiemann M, Chave J (2013) Global wood density database. 2009. Dryad. Identifier: http://hdl. handle. net/10255/dryad, 235. 
Figures

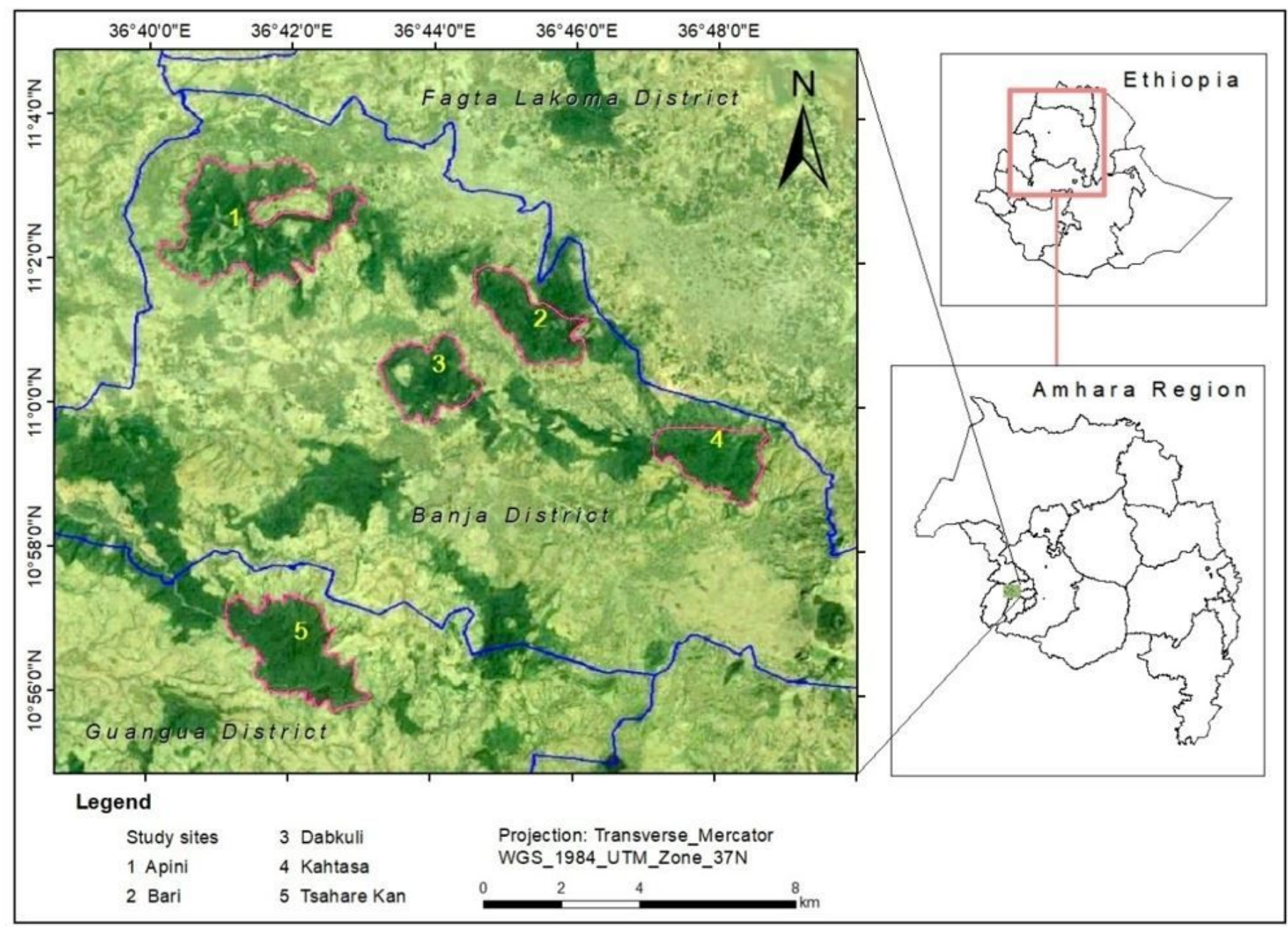

Figure 1

Map of the study area 


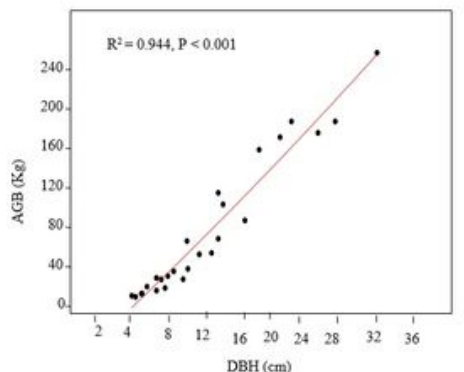

A1. E. cymosa (AGB v DBH)

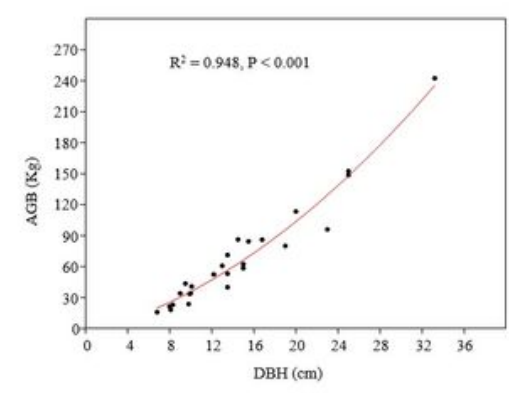

B1. L.volkensii (AGB v DBH)

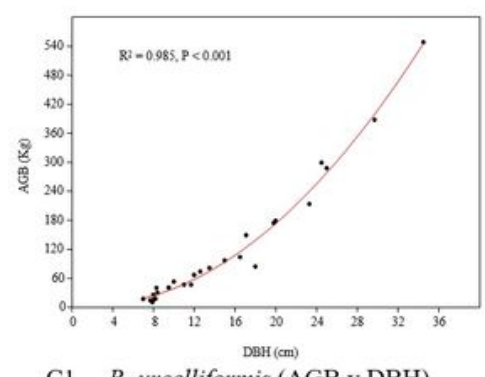

C1. R. urcelliformis (AGB $v \mathrm{DBH})$

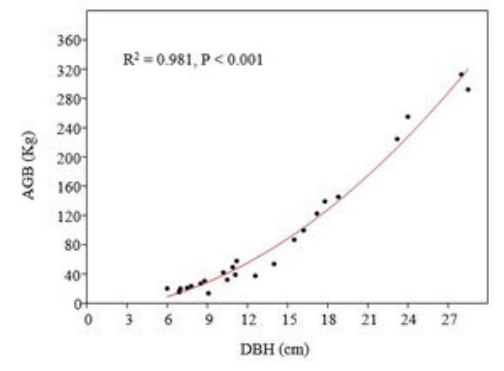

D 1. T. nobilis (AGB v DBH)

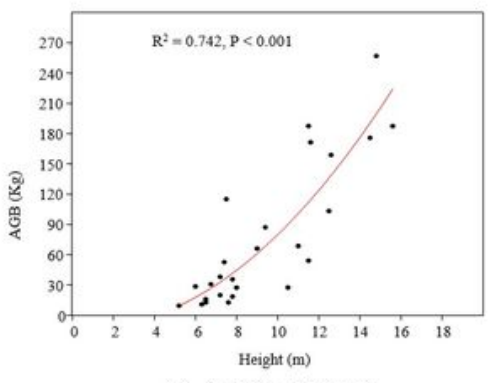

A2. (AGB v Height)

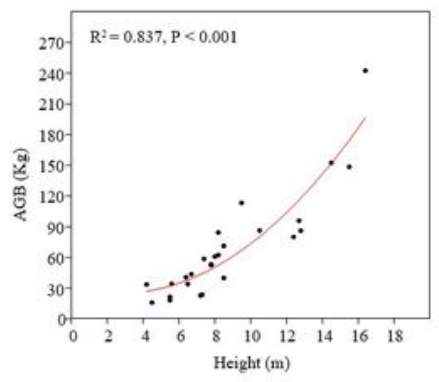

B2. (AGB v Height)
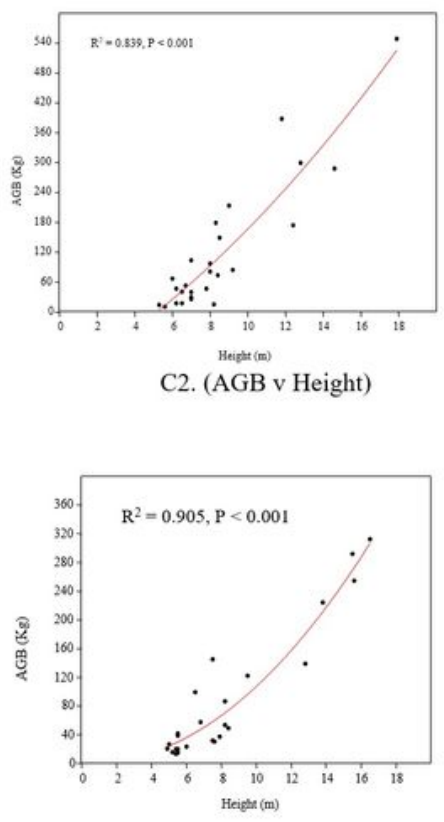

D2. (AGB v Height)

\section{Figure 2}

Regression lines of aboveground biomass (AGB in $\mathrm{kg}$ ) as a function of diameter at breast height (DBH) and height $(\mathrm{H})$ of trees (Key: $\mathrm{R} 2$ = multiple correlation) 


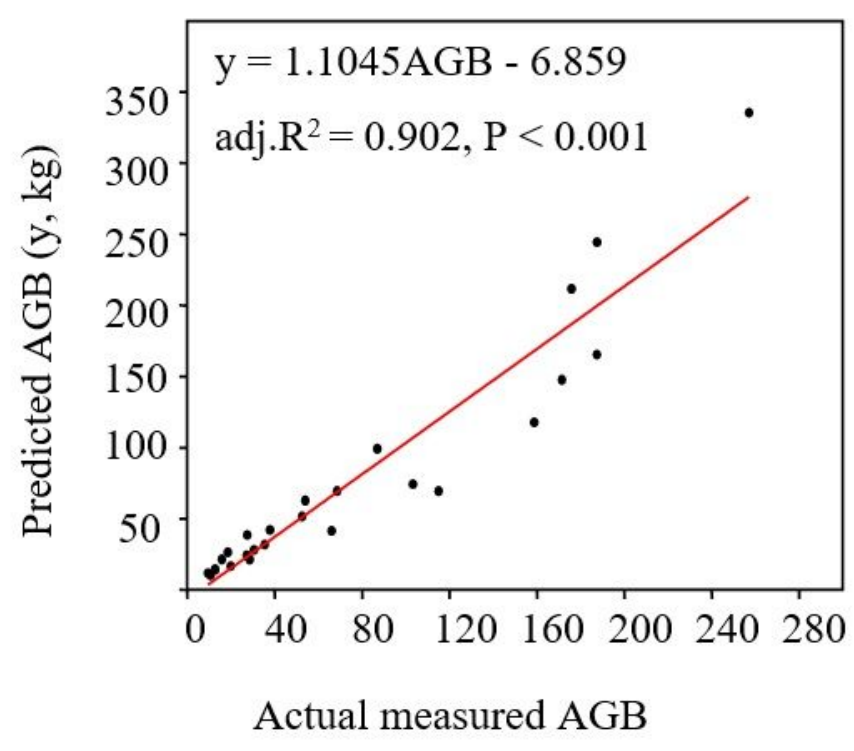

A. E. cymosa

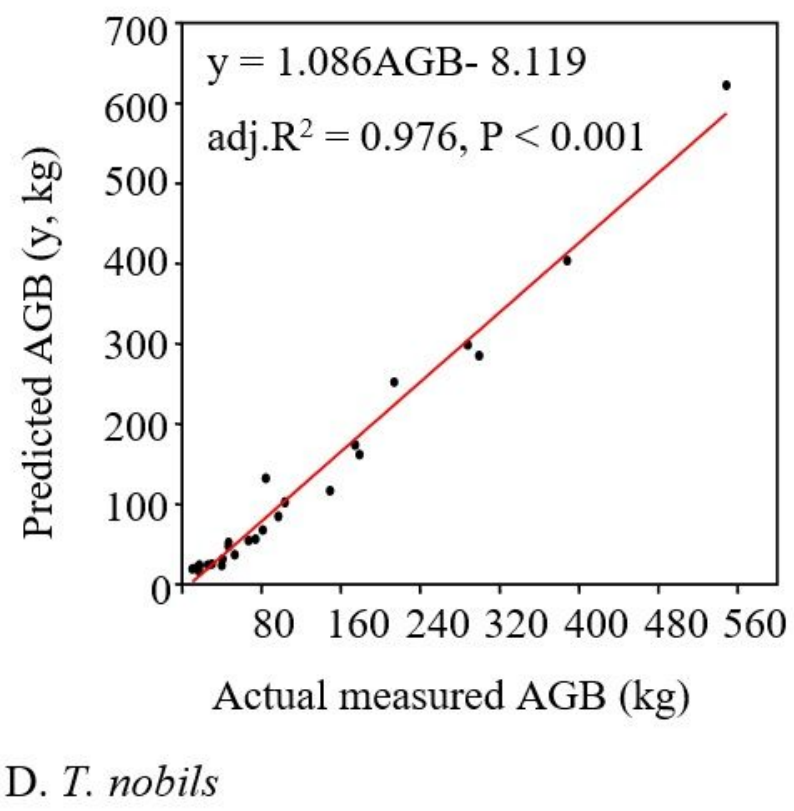

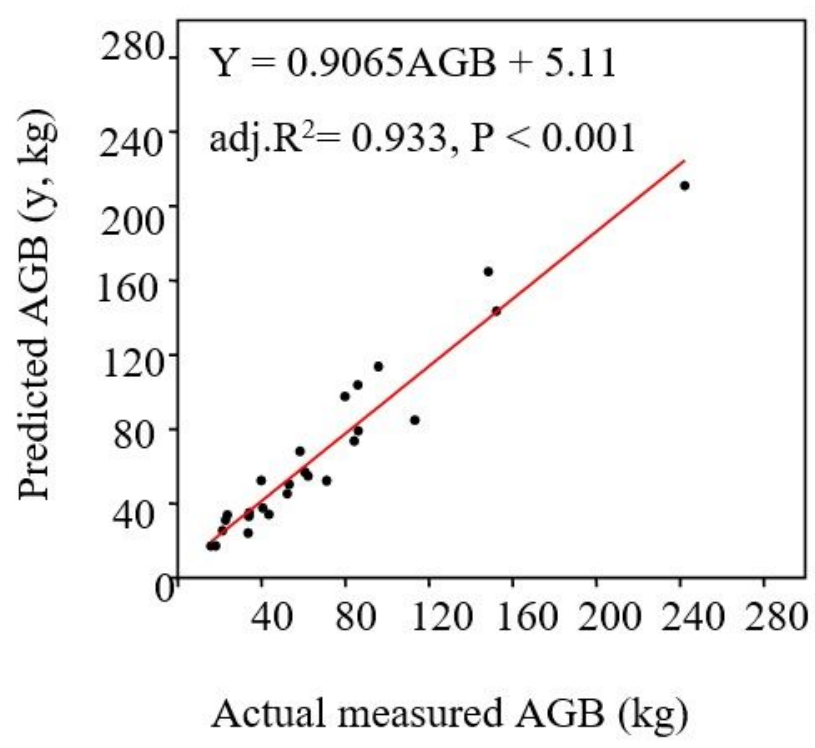

B. L. volkensi

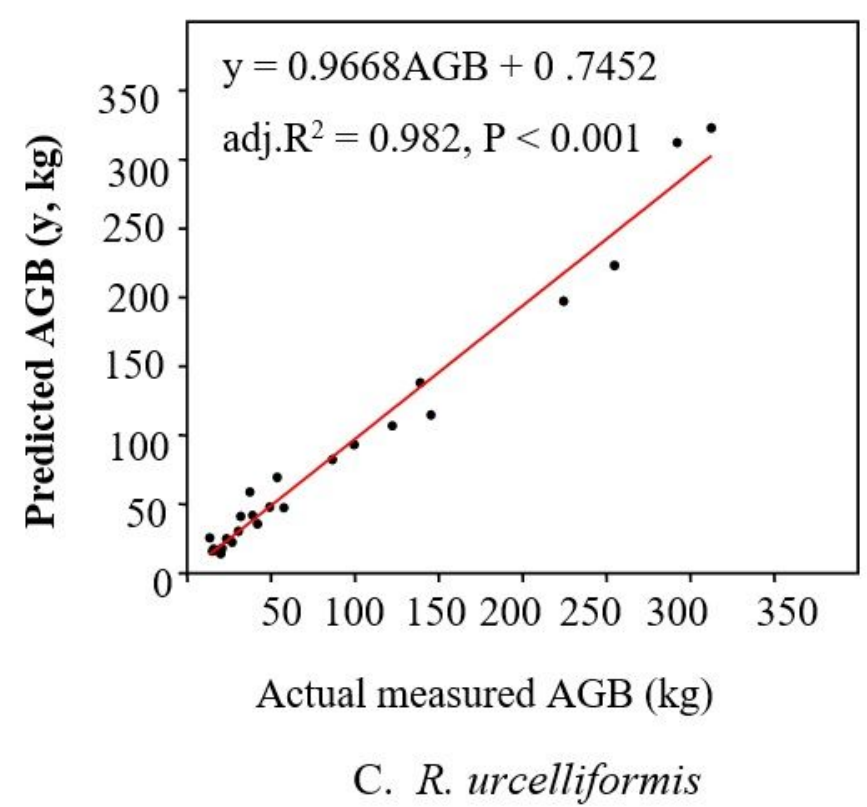

Figure 3

Linear relation between actual measured aboveground biomass against predicted values for the studied species.

\section{Supplementary Files}

This is a list of supplementary files associated with this preprint. Click to download. 
- Tables.docx

- Supplimentarydata.xIsx 